\title{
SUSTAINABLE AGRI-FOOD SUPPLY CHAIN WITH UNCERTAIN DEMAND AND LEAD TIME
}

\author{
Galal, N. M. \& El-Kilany, K. S. \\ Department of Industrial and Management Engineering, \\ Arab Academy for Science, Technology, and Maritime Transport, \\ AbuKir Campus, P.O. Box 1029, Alexandria, Egypt \\ E-Mail: noha.galal@staff.aast.edu, kkilany@aast.edu
}

\begin{abstract}
Food supply, safety and quality have become major concerns worldwide. Agri-food supply chains (ASC) possess special characteristics due to the perishability of their products and the high uncertainty of supply and demand. Furthermore, different sources of $\mathrm{CO}_{2}$ emissions exist in an ASC due to storage, transportation, and disposal of fresh produce. Thus to ensure the sustainability of the supply chain, planning decisions have to be made with consideration of both economic and environmental aspects. This work studies the effect of changing the order quantity in a two-echelon agri-food supply chain on costs, emissions, and service level. A discrete-event simulation model is developed to include stochastic demand and lead-time, the amount of $\mathrm{CO}_{2}$ emissions along the supply chain, service levels, and product lifetime effects. Simulation results show that reducing the order quantities can reduce costs and emissions by $27.42 \%$ and $18.21 \%$; respectively, without sacrificing high service levels. Also, relying on costs or service level as sole objectives of the supply chain without consideration of emissions can result in greater economic and environmental inefficiencies in management of inventory levels.

(Received in October 2015, accepted in February 2016. This paper was with the authors 1 week for 1 revision.)
\end{abstract}

Key Words: Agri-Food Supply Chain, Carbon Emissions, Perishable Goods, Modelling and Simulation

\section{INTRODUCTION}

Agri-food supply chain (ASC) has increasingly attracted the attention of practitioners and academics over the last decade. This is in part driven by the global increasing concern about food supply and quality and the special characteristics this supply chain possesses mainly due to the perishability of its products and the high uncertainties in supply and demand. Two categories of ASC exist: fresh produce products and processed products [1]. This work is concerned with the fresh produce ASC. Fresh produce ASC is differentiated from classical supply chains by the following [1-3]: (i) limited life time of the products and their deterioration over time, (ii) seasonality in production necessitating global sourcing, (iii) special requirements in storage and transportation to preserve quality, and (iv) necessity to comply to national and international regulations relating to food safety and environment. Due to these characteristics ASC are global supply chains extending mostly between developing and developed countries. Although there is a significant increase in the percentage of research published during the period from 2008 to 2013 addressing ASC, only $40 \%$ focuses on developing countries [4].

Models for planning ASC in general are still lagging behind compared to manufacturing supply chains; ASC of fresh produce are even more lagging behind due to the logistical complexities added by their limited shelf life [5]. Models that promise reduced deterioration of perishable products with limited shelf life need further development to support transportation and inventory decisions [5]; specifically, mathematical models in inventory management usually factor demand and transportation lead time as either deterministic values or stochastic with almost no evidence of using real life values for these two factors [4]. For 
that, discrete-event simulation is considered one of the most important tools that is widely used for the analysis and study of supply chains in general $[6,7]$ due to its ability to handle the challenges imposed by the stochastic nature of demand and other logistical factors such as transportation along with the ability of applying simulation models to real life problems.

Furthermore, environmental issues play a considerable role when managing an ASC [8]. When focusing on $\mathrm{CO}_{2}$ emissions, ASC has various sources for these emissions, which are spread over the supply chain starting from the agricultural phase through the production, distribution and consumption phases. Main activities initiating carbon emissions during these phases are the use of fertilizers, the energy use in production, transportation, and inventory, in addition to the food wastes generated throughout the supply chain due to perished products.

Inventory management imposes a crucial factor in ASC operations. Holding low levels of inventory causes potential economic losses in case of unsatisfied demand. On the other hand, holding excessive inventory levels not only increases the holding costs, but will also lead to additional costs due to possible perishability of goods. In addition, due to the nature of the product held in inventory, controlled temperature environment is usually needed resulting in $\mathrm{CO}_{2}$ emissions due to cooling. Even perished amounts of product result in further $\mathrm{CO}_{2}$ emissions due to waste inflicting an additional environmental burden due to the waste of energy and other resources. Unfortunately, current inventory models consider environmental aspects and waste minimization as secondary objectives with more focus on consumer satisfaction and revenue maximization [4]. Hence, most of the inventory models would be in favour of holding more inventories in face of uncertain demand and lead time.

Thus, the purpose of this paper is to study the effect of changing the order quantity under stochastic demand and lead time in a two-echelon agri-food supply chain on both economic and environmental performance measures of an ASC of perishable goods with limited shelflife (referred to as simply ASC throughout the text).

The uniqueness of this work lies in the fact that the combined complexity effect of stochasticity in demand and lead time and the perishability of the product are taken into consideration. Furthermore, the work lays more emphasis on the effect of operating the ASC on the environmental aspects represented by $\mathrm{CO}_{2}$ emissions resulting from the different operations and from waste of product due to its perishability. Finally, a real-life case study is presented; where, actual data is used to drive a discrete-event simulation model and to study the effect of changing the order size on inventory levels, costs associated with it, and $\mathrm{CO}_{2}$ emissions. The choice of simulation for modelling and solution allows for the incorporation of stochastic parameters intrinsic to real life problems. It further allows for a detailed analysis of system performance, thus giving insights to managerial decisions. The remainder of this paper is structured as follows. Section 2 presents a literature review of environmental efficient practices in managing perishable inventory items. In Section 3 the addressed problem is defined and formulated. A case study of a real-life ASC is presented in Section 4; while, the results and analysis of the developed discrete-event simulation model are presented in Section 5. Finally, conclusions are drawn and potential areas for future research are highlighted in Section 6.

\section{LITERATURE REVIEW}

This section reviews inventory decisions for perishable agri-food supply chains and concentrates on perishability and environmental impact of ASC operations. Inventory control of perishable items has been extensively tackled in literature. A comprehensive review of perishable inventory is presented in $[9,10]$. Both reviews classified models for deteriorating inventory according to product lifetime and demand characteristics; yet, both did not consider environmental implications of perishable inventory items. Traditional inventory policies were 
applied to perishable food products and simulation was used to find the optimal settings of the inventory models parameters while considering shelf-life constraints [11]. Simulation was also used in evaluating order policies in a supply chain of fresh produce and including costs to reflect losses in shelf life of products [12]. Although both models considered perishability when determining order quantities, they focused on minimization of costs and other performance measures with no regard to environmental impact of supply chain operations.

Environmental aspects of inventory management have been tackled in literature for nonperishable products. However, considering environmental impact of perishable inventory is scarce [13]. Classical economic order quantity incorporated environmental aspects of managing inventory to arrive at an inventory policy for any type of product that satisfies the traditional cost objective at a minimal environmental impact [14-17].

A number of papers have been published to cover the environmental footprint of inventory of perishable items. Examples of research conducted in this field are [13, 18-22] which consider general perishable products, with the exception of [22], which investigates a perishable ASC. It is observed that all models account for classical costs elements combined with the environmental impact of the supply chain. Different approaches were adopted to deal jointly with the cost and emissions objectives such as integration of several objectives through $\varepsilon$-constraint method [13] or compromise programming [19, 20].

The environmental impact in all of the reviewed work is measured in quantities of $\mathrm{CO}_{2}$ only or total greenhouse gases (GHG) expressed as $\mathrm{CO}_{2 \mathrm{eq}}$ emitted from the different supply chain activities. The common source of emissions considered in all reviewed research is transportation; other sources such as cooling [18,22] and recycling [20] were also considered.

As to the uncertainty aspects of the perishable inventory, stochastic demand is only modelled in two cases $[20,22]$ either using stochastic programming or simulation modelling. In order to ensure environmental sustainability, risks associated with product quality deterioration through the supply chain are sought to be minimized in [19] along with the costs and wastage objectives.

It is obvious that the environmental and stochastic aspects of perishable inventory have hardly been jointly addressed in the literature of the ASC. Thus the current research contributes to the ASC research by the following; (i) a simulation model of perishable inventory replenishment policy in a two-echelon ASC is developed to analyse the effect of changing the order quantity on inventory cost and emissions generated while satisfying a desirable service level, (ii) three sources of emissions are considered; emissions resulting from transportation, cooling and waste, (iii) two sources of uncertainty are modelled, which are demand and lead time thus approaching real life situation, and (iv) the simulation model is applied to a real-life case study for an international two echelon supply chain using real values for demand and lead time.

\section{PROBLEM DEFINITION}

\subsection{Supply chain activities}

Consider an ASC consisting of two echelons; a producer $(i)$ and a distributor $(j)$ of a single fresh product. The activities at the producer are as follows: upon receipt of quantity $\left(Q_{i}^{t}\right)$ of the fresh product with an initial lifetime of $(M)$ periods, the product is inspected to check whether it is damaged, of lower grade, or of smaller expected lifetime. Products failing to pass the quality check are disposed of or sold at a lower price. Good products are processed and then stored in a temperature controlled environment and are shipped to the distributor on daily basis. As mentioned before, ASCs are global supply chains extending mostly between developing and developed countries and thus usually both truck and water transportation are needed to move the product from the producer country to the distributer country. 
After transportation, quantities arriving at the distributor $\left(q_{i j}^{t}\right)$ are dispatched to the retailer according to a first in first out (FIFO) policy. The residual life of the items stored at the distributer is checked at the end of each period before sending these items to the retailer. A minimum allowable residual life value $(\tau)$ is required for the product in order to reach the retailer with an acceptable remaining shelf life. Outdated items having a remaining life less than $(\tau)$ are considered perished and are disposed of.

\subsection{Sources of emissions}

There are different sources of emissions resulting from the agri-food supply chain. In this work, $\mathrm{CO}_{2}$ emissions resulting from cooling, transportation, and perished product disposal are considered. Due to perishable nature of the product it should be kept at temperature controlled environment during storage at the producer and the distributor resulting in cooling emissions at both echelons. During transportation, the product should also be cooled, resulting in even more cooling emissions in addition to transportation emissions; as shown in Figure 1. Finally, emissions are also generated when disposing of perished products.

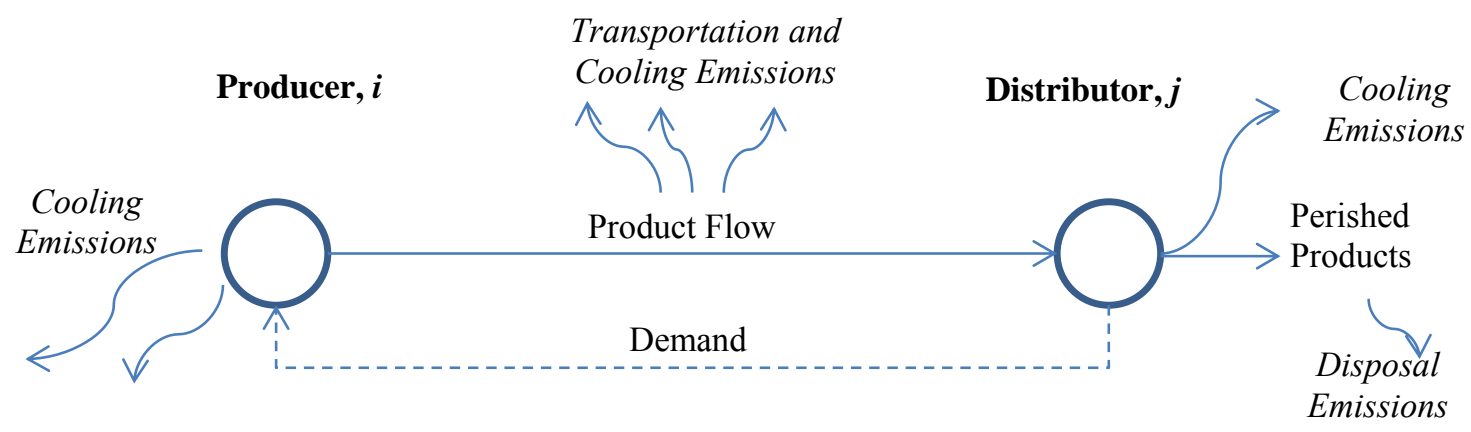

Figure 1: Product and information flow in a two-echelon supply chain [based on [23]].

\subsection{Problem statement}

Based on the previous description, the problem is to determine the order quantity that the producer has to place per period $t\left(Q_{i}^{t}\right)$ in order to meet the variable distributer demand. This order quantity has to be greater than the distributer demand $\left(D_{j}^{t}\right)$ due to the losses encountered throughout the supply chain and due to the variable producer-distributer lead time resulting from the different modes of transportation employed. The excess quantity that the producer has to order is expressed as a percentage $(\alpha)$ of the demand, $D_{j}^{t}$ as in Eq. (1).

$$
Q_{i}^{t}=D_{j}^{t}(1+\alpha) \quad \forall i, j
$$

The objective is to determine the effect of changing the $\alpha$ percentage and; hence, the order quantities, on the total supply chain costs, carbon emissions, and service level $(S L)$ while using stochastic demand and lead-time. Further model assumptions are as follows:

- No quantities are lost during transportation.

- Ordering and unit transportation costs are constant.

- No backorders are allowed. Unsatisfied demand is lost.

- Selling price of each unit is constant and independent of product age.

- No shortages at producer.

- Warehouses capacity is unlimited. 


\subsection{Supply chain costs}

Total supply chain costs per period $t$ in Eq. (2) include the following elements: processing costs incurred at the producer and the distributer, shortage, and transportation costs. Costs incurred at the producer per unit product include: processing $\left(c p_{i}\right)$, holding $\left(h_{i}\right)$, and disposal $\left(c w_{i}\right)$ costs for a fraction $(\beta)$ failing to satisfy quality requirements. The total transportation cost $\left(C T_{i j}\right)$ includes both truck and water transportation. Costs incurred at the distributer per unit product include: processing $\left(c p_{j}\right)$, holding $\left(h_{j}\right)$, disposal of perished items $\left(c w_{j}\right)$, and shortage costs $\left(c_{s}\right)$ that are incurred due shortages $\left(S_{j}^{t}\right)$ at any period $t$. The quantities on hand at the distributor with a residual life $(r)$ at the end of period $t$ are represented by the vector $\left(x_{j, r}^{t}\right)$; where, the status of these quantities is updated at the end of each period after satisfying the period's demand and disposal of outdated quantities $\left(O_{j}^{t}\right)$ with a residual life $(r \leq \tau)$.

$$
T C^{t}=q_{i}^{t}\left(c p_{i}+h_{i}+c w_{i} \beta\right)+q_{i j}^{t} C T_{i j}+q_{i j}^{t} c p_{j}+h_{j} \sum_{r=1}^{\tau} x_{j, r}^{t}+c w_{j} O_{j}^{t}+c_{S} S_{j}^{t}
$$

Since, the type of product flowing through the supply chain is food, the cost of disposing the product goes beyond its purchasing cost. The cost of disposing any quantity is composed of the sum of all costs incorporated until the stage of disposal in addition to waste processing cost. In such a way the disposal of products is penalized, which is necessary due to the nature and value of the product in food supply chains.

\subsection{Carbon gas emissions}

Three sources of emissions are considered in this model; these are cooling emissions from stored and transported items, $E_{c}$ in Eq. (3); emissions resulting from transportation by truck and water, $E_{T R}$ in Eq. (4); and emissions resulting from disposal of waste products, $E_{d}$ in Eq. (5). $\mathrm{CO}_{2}$ emissions resulting from cooling $\left(e_{c}\right)$, truck transportation $\left(e_{T}\right)$, water transportation $\left(e_{w}\right)$, and disposal $\left(e_{d}\right)$ are measured in kilogram weight of $\mathrm{CO}_{2}$ emitted throughout the chain per unit of product.

$$
\begin{gathered}
E_{c}=e_{c}\left(q_{i}^{t}+q_{i j}^{t}+x_{j, r}^{t}\right) \\
E_{T R}=e_{T} q_{i j}^{t}+e_{w} q_{i j}^{t} \\
E_{d}=e_{d} O_{j}^{t}
\end{gathered}
$$

\subsection{Service level}

The third performance indicator is the service level in Eq. (6) is expressed as the fill rate, which is the amount of demand $\left(D_{j}^{t}\right)$ fulfilled from the quantity on hand during each period $t$.

$$
\frac{D_{j}^{t}-S_{j}^{t}}{D_{j}^{t}} \geq S L \quad \forall i, j, \text { and } t
$$

Shortage quantities at each period $\left(S_{j}^{t}\right)$ are represented in Eq. (7) as the maximum of zero and the difference between the retailer's demand and the sum of all quantities on hand at the distributor with a residual life of $(\tau)$ or greater.

$$
S_{j}^{t}=\left(D_{j}^{t}-\sum_{r=\tau}^{M} x_{j, r}^{t}\right)^{+} \quad \forall j \text { and } t
$$




\section{CASE STUDY}

The proposed model has been applied to an actual agri-food supply chain extending between Egypt (producer) and Netherlands (distributor). One type of fruit, oranges, is considered to flow through the network. According to the Food and Agriculture Organization of the United Nations (FAO), Egypt is the $7^{\text {th }}$ worldwide exporter of oranges [24]. This fact emphasizes the economic importance and size of the product being dealt with.

\subsection{Operational data}

Demand by retailers in Europe is collected by the distributor in the Netherlands each week. The distributor then reports the weekly demand to the producer in Egypt. Quantities arrive at the producer from suppliers batched in pallets daily. Oranges are sent to a washing facility and are then dried and inspected. Based on their quality level, oranges are classified in one of three categories; defective to be disposed of, lower quality to be sold in open market, and good products to be stored in a temperature controlled room to be further shipped to the distributor. The producer applies stringent quality control to ensure the quality of the products to meet consumer's requirements. Historical data for one year have been collected, and analysed to identify the percentage of defective and low quality products. It was observed that on the average $3 \%$ and $7 \%$ of the quantities arriving from the supplier are disposed of and sold to open market, respectively.

Multi-modal transportation is used in the current supply chain, where temperature controlled containers are loaded on trucks until the port. Sea freight to the distributor is then used. At the destination port, trucks are again used to transport the temperature controlled containers to the distributor's facility. When arriving at the distributor, pallets are stored in a temperature controlled warehouse and their quality is checked on daily basis. Products having a remaining shelf life less than 10 days are disposed of.

The supply chain is operating on a no backorder policy and any unmet demand is considered as lost sales. In addition, due to the risks associated with demand and lead time uncertainties and the risk associated with the quality of oranges at the producer and the distributor; normally, excess amounts are ordered weekly by the producer. Based on historical records of demand and order quantities, this excess quantity ordered in the actual ASC is on average $30 \%$ of the stated demand.

\subsection{Numerical data}

A number of probability distributions representing the demand, transportation, and the operations performed at both producer and distributor are used. These distributions are based on actual historical data collected at the facilities and fitted using Stat::Fit ${ }^{\circledR}$. Furthermore, deterministic data representing the different model parameters have been collected and/or calculated for the current study. Table I lists these deterministic parameters; where, all monetary values are expressed in producer's currency (EGP). Waste cost at producer and distributor include all costs incurred until disposal in addition to $10 \%$ of the unit purchasing cost to account for waste processing. Fixed costs do not affect the decision on the order quantity. Thus fixed ordering cost and sales price to open market are neglected. The latter is constant, since a constant percentage of products $(7 \%)$ is sold to open market. Shortage cost is calculated as lost profit cost, which is the difference between the selling price and unit production cost. Holding cost at both distributor and producer is mainly electricity cost used for cooling. 
Table I: Model parameters values.

\begin{tabular}{|c|l|c|l|}
\hline Parameter & Value & Parameter & Value \\
\hline$c p_{i}$ & $300 \mathrm{EGP} /$ ton & $c p_{j}$ & $125 \mathrm{EGP} /$ ton \\
\hline$c w_{i}$ & $2,850 \mathrm{EGP} /$ ton & $h_{j}$ & $216 \mathrm{EGP} /$ ton \\
\hline$h_{i}$ & $192 \mathrm{EGP} /$ on & $e_{C}$ & $0.3273 \mathrm{~kg}$ of $\mathrm{CO}_{2} / \mathrm{hr} /$ ton of product \\
\hline$c_{s}$ & $3,280 \mathrm{EGP} / \mathrm{ton}$ & $e_{T}$ & $92.275 \mathrm{~kg}$ of $\mathrm{CO}_{2} /$ ton shipped \\
\hline$C T_{i j}$ & $130 \mathrm{EGP} /$ ton & $e_{w}$ & $154.32 \mathrm{~kg}$ of $\mathrm{CO}_{2} /$ ton shipped \\
\hline$c w_{j}$ & $3,720 \mathrm{EGP} /$ ton & $e_{d}$ & $620 \mathrm{~kg} \mathrm{of} \mathrm{CO} /$ ton of product \\
\hline
\end{tabular}

As to emission factors, three sources of emissions are considered in the model; emissions from electricity used in cooling, truck and water transportation, and emissions from disposal of oranges. For the first source the emission factor is calculated by dividing the annual total $\mathrm{CO}_{2}$ quantity generated by electricity generation in Egypt (86 Mton [25]) by the total power generated by all thermal power plants in Egypt in the same year of 2011 (129 GWh [26]). This results in an emission factor of $6.648 \times 10^{-4}$ ton of $\mathrm{CO}_{2} / \mathrm{kWh}$. Finally, water and road transportation emissions are adopted from [27] and waste disposal emissions from [28].

\section{SIMULATION, RESULTS, AND ANALYSIS}

A simulation model for the ASC presented in the previous section is developed in the ExtendSim v9.0 simulation environment. The purpose of the model is to study and analyse the effect of changing the $(\alpha)$ percentage on the supply chain costs, emissions, and service level. The model is developed with the flexibility of changing the $(\alpha)$ value and collecting the required outputs for the different experiments without the need to alter the model.

\subsection{Performance metrics}

In order to evaluate the system performance when using different order quantities, a number performance metrics are used for the evaluation. Values for these measures are reported daily and are averaged over considerably long simulation runs and for more than one replication (as will be indicated in the simulation setup). The measures reported by the simulation experiments fall into three categories: costs, emissions, and service level. The developed simulation models report the average total values of costs and emissions as well as their constituent elements (i.e. holding, production, waste, shortage, and transportation costs; and cooling, transportation, and waste emissions).

\subsection{Simulation setup}

The simulation parameters are typically the warm up period, the replication length, and the number of replications. Selecting the simulation parameters is vital to obtaining accurate simulation results. To remove any initialization bias, the warm up period has been determined by the Welch's method and set at 100 days. All three performance indicators have been investigated and the one requiring the longest time to reach steady state has been used to determine the warm-up period. In order to ensure that a sufficient amount of data has been generated in an experiment, a run length of 2 years (equivalent to 728 days) is selected and 15 replications for each experiment are performed. Thus the reported values for each experiment are averages of 10,920 data points. Number of replications was determined using the confidence interval method based on a confidence interval of $95 \%$. Again this choice has been made by considering all three performance indicators. Finally, common random numbers are used in all experiments to control the variability in the results and to ensure that the results reflect the effect of changing the order quantity while reducing the effect of the randomness in the model. 


\subsection{Base model results and analysis}

A summary of the results obtained for the base case describing the currently applied replenishment policy is given in Table II. Due to the conservative policy of ordering $30 \%$ more than the required quantities to cope with demand variability, the large amounts of on hand and perished quantities (reflected in average holding and perished cost per day) indicate the presence of inefficiencies in the current system. However, a high service level is achieved $(99.86 \%)$, which is confirmed by the negligible amount of daily shortage cost. Before proceeding further with the analysis, the results obtained from the base model in terms of quantities sold, perished, transported, etc. were confirmed by the supply chain manager.

Table II: Summary of results for the base case.

\begin{tabular}{|l|c|l|c|}
\hline Cost Item & EGP/Day & Emissions & ${\mathrm{Kg} \mathrm{of} \mathrm{CO}_{2}}$ \\
\hline Holding Cost & $44,215.26$ & Cooling & $5,704.59$ \\
\hline Perished Cost & $25,607.69$ & Disposal & $4,478.46$ \\
\hline Transportation Cost & $5,685.67$ & Transportation & $10,621.65$ \\
\hline Production Cost & $5,302.41$ & Total Emissions & $\mathbf{2 0 , 8 0 4 . 7 0}$ \\
\hline Shortage Cost & 172.79 & \multicolumn{2}{|l}{} \\
\hline Total Costs & $\mathbf{8 0 , 9 8 3 . 8 2}$ & Service Level & $\mathbf{9 9 . 8 6 ~ \% ~}$ \\
\hline
\end{tabular}

\subsection{Effect of changing the order quantity}

To understand the effect of varying the order quantity on the different performance measures; cost, emissions, and service level, the $(\alpha)$ percentage is varied from $5 \%$ to $30 \%$.

Fig. 2 shows that both total emissions and costs, behave similarly with respect to the excess percentage of order quantity; where, decreasing $(\alpha)$ results in decreasing both costs and emissions. Yet, total costs behave differently for lower values of $(\alpha)$; where, total costs tends to stabilise. This is due to the fact that reduced order quantities would result in more shortage; and, hence an increase in shortage cost as shown in Fig. 3.

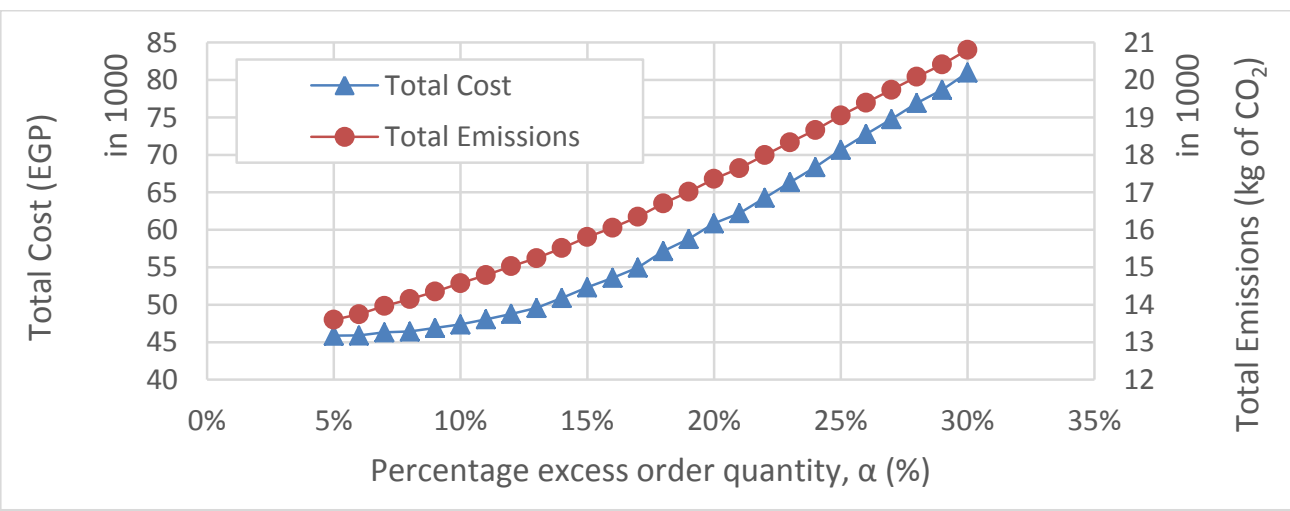

Figure 2: Effect on changing excess percentage $(\alpha)$ on total costs and emissions.

Further investigation of the relationship between total costs and total emissions is shown in Fig. 4. The figure shows that reduction of the order quantity will result in reduction of both total emissions and total costs with the same proportion as clearly indicated by the linear portion of the graph. However, when further reducing the order quantities, emissions decrease at a higher rate and total costs starts to stabilise due to the effect of shortage cost. Thus, if the traditional cost reduction is considered as the sole objective for this problem, one would be reluctant to further reduce the order quantities and; hence, missing an opportunity for further 
improving the environmental performance of the supply chain. Service level performance is depicted in Fig. 5; where, service level increases with the increase of the excess order quantity. A sharp increase is observed for $\alpha$ values ranging from $5 \%$ to $19 \%$. Beyond $19 \%$ no major changes occur and a service level of $99 \%$ and higher is achieved.

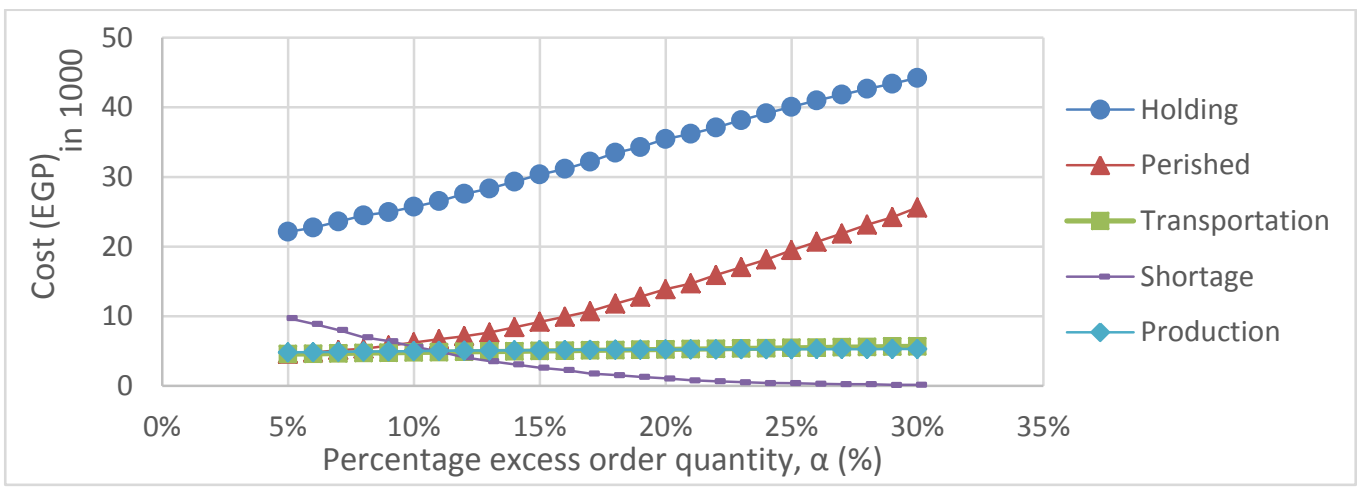

Figure 3: Change in costs elements with respect to $\alpha$.

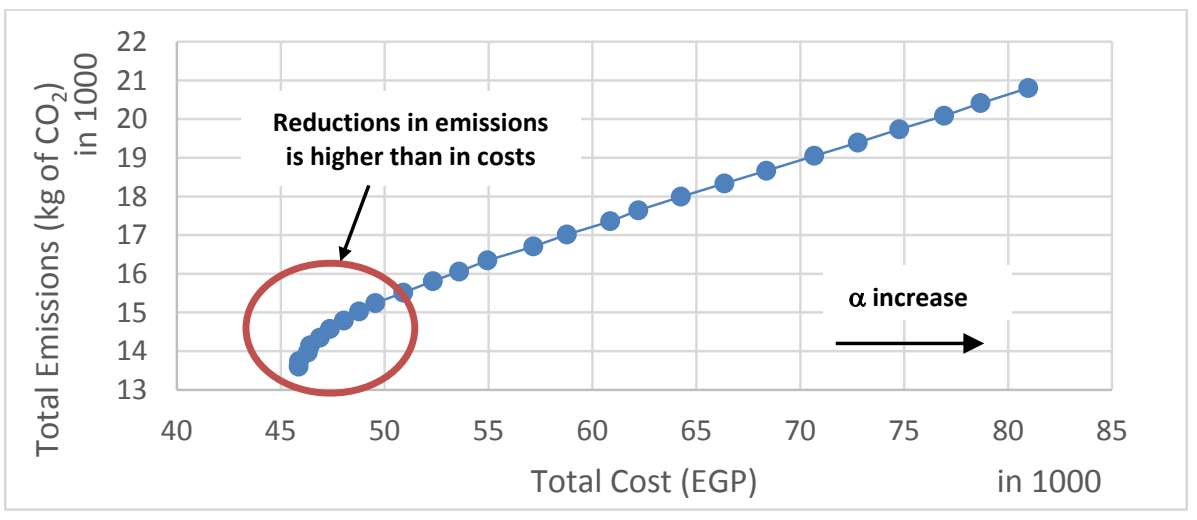

Figure 4: Relationship between total costs and total emissions for different $\alpha$ values.

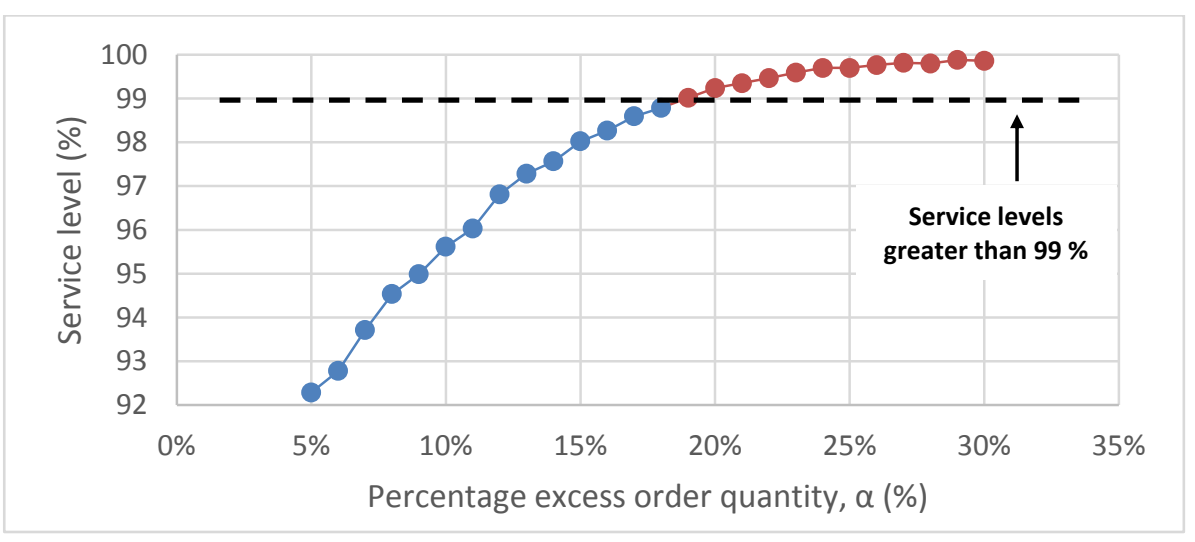

Figure 5: Effect of changing excess percentage $(\alpha)$ on service level.

Fig. 6 shows the relation between all three performance measures: costs, emissions, and service level for the different $\alpha$ values. The graph shows that for a service level between 92.28 and $98 \%$, the costs and emissions show slow increases. For a service level above $98 \%$, both costs and emissions increase at a higher rate. Increasing the service level beyond $99 \%$, causes a sharp increase in costs and emissions, this is unjustifiable in terms of costs and/or emissions. This indicates the inefficiencies in the supply chain under study and also shows that a large amount of emissions and costs can be saved without sacrificing the high service 
level. With reference to both Fig. 5 and Fig. 6, a $99.02 \%$ service level is achievable with an excess order quantity $(\alpha)$ of $19 \%$, would result in a total cost of EGP 58,780 and total emissions of $17,015 \mathrm{~kg}$ of $\mathrm{CO}_{2}$. Meaning that, reducing the order quantity will decrease the total cost by $27.42 \%$ and the total emissions by $18.21 \%$ while only sacrificing $0.84 \%$ of the current service level.

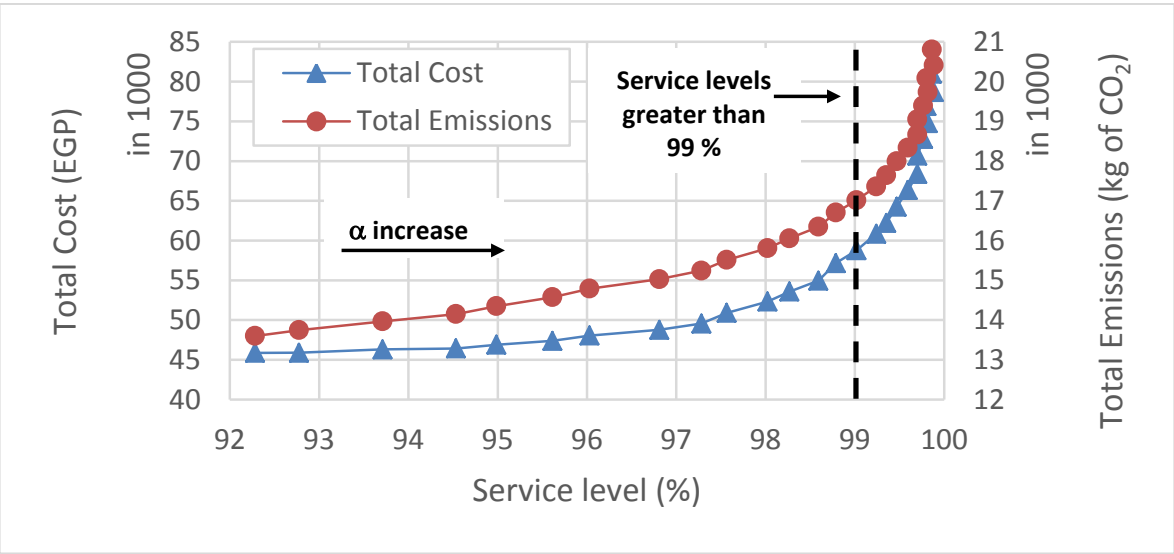

Figure 6: Relationship between total costs, emissions, and service level for different $\alpha$ values.

It is also noteworthy to mention that increasing the excess quantity increases the disposal costs, as more products are perished. Using an $(\alpha)$ value of $19 \%$ would result in a disposal cost of EGP 12,802 compared to a disposal cost of EGP 25,607 at an $(\alpha)$ value of $30 \%$, which is almost $50 \%$ reduction in perished costs and; consequently, reduction in perished quantities and disposal emissions by similar amounts. Thus, the recommended replenishment policy not only reduces costs and emissions, but also meets the target of decreasing the amount perished which is critical to the studied perishable food supply chain.

\section{CONCLUSIONS}

This work studied the management of inventory in a perishable good supply chain with stochastic demand and lead time and with consideration of the environmental aspects of operating the supply chain. The objective is to study the effect of changing the order quantity on total supply chain cost, emissions, and service level. To this end, the problem under study has been well defined, formulated, and solved using simulation. Formulation presented differs from commonly used formulation of the perishable inventory systems by relating the order quantity to customer demand directly. This simplifies the application and interpretation of the model in real life cases. The model also helps in the consideration of important features inherent to perishable good supply chains, namely product limited life time and product quality, in addition to the stochastic nature of the demand and lead time. Three sources of emissions have also been modelled; multi-modal transportation emissions, cooling emissions, and disposal emissions.

The simulation model has been run using stochastic data derived from real life values based on case study of an agri-food supply chain consisting of two echelons and extending between two countries. The results reveal that the incorporation of carbon emissions in the decision making process does not negatively impact the service level. Although a slight reduction in service level occurred, other critical system performance measures improved considerably. Thus, there is no contradiction or extra cost for incorporating environmental objective, as some decision makers presume especially in developing countries. In fact, the consideration of carbon emissions in the decision making process reduced the average total cost for the selected case scenario by $27.42 \%$ from the base case (with a $50 \%$ reduction in 
perished costs and quantities) and reduced the total emissions by $18.21 \%$ while reducing service level by only $0.84 \%$.

Agri-food supply chains typically extend between developed and developing countries, complicating thus the decision making process due to the considerable differences in environmental legislation and in perceiving environmental impact importance by supply chain actors. One of the problems facing developing countries is the limited availability and accuracy of environmental data. The other is the lack or limited existence of environmental legislation, which makes it difficult to include emissions as another objective for the model or even set upper limits for emissions when modelled as constraints.

Areas to be considered for future research include the study of different environmental management policy as cap and trade systems. Further sources of emissions as the impact of packaging material may also be considered.

\section{ACKNOWLEDGEMENTS}

Data provided for the real life case study has been generously offered by Ms. Sherine Beshara who partially gathered this data during her postgraduate studies and continued to support the authors with all additional information required for this work. All developed models are built using the ExtendSim ${ }^{\mathrm{TM}}$ Suite $\mathrm{v} 9.0$ simulation environment from ImagineThat, Inc. The tool has been offered to the department of Industrial and Management Engineering, AASTMT, as a grant for teaching and research purposes as part of the ExtendSim Adopter Program.

\section{REFERENCES}

[1] Van der Vorst, J. G. A. J. (2006). Performance measurement in agri-food supply-chain networks An overview, Ondersteijn, C. J. M.; Wijnands, J. H. M.; Huirne, R. B. M.; Van Kooten, O. (Eds.), Quantifying the Agri-Food Supply Chain, Springer, Dordrecht, 13-24

[2] Van der Vorst, J. G. A. J. (2000). Effective Food Supply Chains - Generating, Modelling and Evaluating Supply Chain Scenarios, PhD-thesis, Wageningen University, Wageningen

[3] Tsolakis, N. K.; Keramydas, C. A.; Toka, A. K.; Aidonis, D. A.; Iakovou, E. T. (2014). Agrifood supply chain management: A comprehensive hierarchical decision-making framework and a critical taxonomy, Biosystems Engineering, Vol. 120, 47-64, doi:10.1016/j.biosystemseng. 2013.10.014

[4] Shukla, M.; Jharkharia, S. (2013). Agri-fresh produce supply chain management: A state-of-theart literature review, International Journal of Operations \& Production Management, Vol. 33, No. 2, 114-158, doi:10.1108/01443571311295608

[5] Ahumada, O.; Villalobos, J. R. (2009). Application of planning models in the agri-food supply chain: A review, European Journal of Operational Research, Vol. 196, No. 1, 1-20, doi:10.1016/j.ejor.2008.02.014

[6] Al-Hawari, T.; Ahmed, A.; Khrais, S.; Mumani, A. (2013). Impact of assignment, inventory policies and demand patterns on supply chain performance, International Journal of Simulation Modelling, Vol. 12, No. 3, 164-177, doi:10.2507/IJSIMM12(3)3.235

[7] Buchmeister, B.; Friscic, D.; Lalic B.; Palcic, I. (2012). Analysis of a three-stage supply chain with level constraints, International Journal of Simulation Modelling, Vol. 11, No. 4, 196-210, doi:10.2507/IJSIMM11(4)3.212

[8] Soto-Silva, W. E.; Nadal-Roig, E.; González-Araya, M. C.; Pla-Aragones, L. M. (2016). Operational research models applied to the fresh fruit supply chain, European Journal of Operational Research, Vol. 251, No. 2, 345-355, doi:10.1016/j.ejor.2015.08.046

[9] Goyal, S. K.; Giri, B. C. (2001). Recent trends in modeling of deteriorating inventory, European Journal of Operational Research, Vol. 134, No. 1, 1-16, doi:10.1016/S0377-2217(00)00248-4

[10] Bakker, M.; Riezebos, J.; Teunter, R. H. (2012). Review of inventory systems with deterioration since 2001, European Journal of Operational Research, Vol. 221, No. 2, 275-284, doi:10.1016/j.ejor.2012.03.004 
[11] Bottani, E.; Ferretti, G.; Montanari, R.; Rinaldi, M. (2014). Analysis and optimisation of inventory management policies for perishable food products: a simulation study, International Journal of Simulation and Process Modelling, Vol. 9, No. 1-2, 16-32, doi:10.1504/ IJSPM.2014.061429

[12] Rijpkema, W. A.; Rossi, R.; van der Vorst, J. G. A. J. (2014). Effective sourcing strategies for perishable product supply chains, International Journal of Physical Distribution \& Logistics Management, Vol. 44, No. 6, 494-510, doi:10.1108/IJPDLM-01-2013-0013

[13] Soysal, M.; Bloemhof-Ruwaard, J. M.; van der Vorst, J. G. A. J. (2014). Modelling food logistics networks with emission considerations: The case of an international beef supply chain, International Journal of Production Economics, Vol. 152, 57-70, doi:10.1016/j.ijpe.2013.12.012

[14] Bonney, M.; Jaber, M. Y. (2011). Environmentally responsible inventory models: Non-classical models for a non-classical era, International Journal of Production Economics, Vol. 133, No. 1, 43-53, doi:10.1016/j.ijpe.2009.10.033

[15] Arslan, M. C.; Turkay, M. (2013). EOQ revisited with sustainability considerations, Foundations of Computing and Decision Sciences, Vol. 38, No. 4, 223-249, doi:10.2478/fcds-2013-0011

[16] Hua, G.; Cheng, T. C. E.; Wang, S. (2011). Managing carbon footprints in inventory management, International Journal of Production Economics, Vol. 132, No. 2, 178-185, doi:10.1016/j.ijpe.2011.03.024

[17] Tao, Z.; Guiffrida, A. L.; Troutt, M. D. (2010). A green cost based economic production / order quantity model, Proceedings of the $1^{\text {st }}$ Annual Kent State International Symposium on Green Supply Chains, 210-223

[18] Bozorgi, A.; Pazour, J.; Nazzal, D. (2014). A new inventory model for cold items that considers costs and emissions, International Journal of Production Economics, Vol. 155, 114-125, doi:10.1016/j.ijpe.2014.01.006

[19] Ren, Z.; Saengsathien, A.; Zhang, D. (2013). Modeling and optimization of inventory and sourcing decisions with risk assessment in perishable food supply chains, 2013 IEEE International Conference on Industrial Engineering and Engineering Management (IEEM), 934939, doi:10.1109/IEEM.2013.6962549

[20] Sazvar, Z.; Mirzapour Al-e-hashem, S. M. J.; Baboli, A.; Akbari Jokar, M. R. (2014). A biobjective stochastic programming model for a centralized green supply chain with deteriorating products, International Journal of Production Economics, Vol. 150, 140-154, doi:10.1016/j.ijpe.2013.12.023

[21] Soysal, M.; Bloemhof-Ruwaard, J. M.; Haijema, R.; van der Vorst, J. G. A. J. (2015). Modeling an inventory routing problem for perishable products with environmental considerations and demand uncertainty, International Journal of Production Economics, Vol. 164, 118-133, doi:10.1016/j.ijpe.2015.03.008

[22] Van der Vorst, J. G. A. J.; Tromp, S.-O.; van Der Zee, D.-J. (2009). Simulation modelling for food supply chain redesign; integrated decision making on product quality, sustainability and logistics, International Journal of Production Research, Vol. 47, No. 23, 6611-6631, doi: $10.1080 / 00207540802356747$

[23] Minner, S.; Transchel, S. (2010). Periodic review inventory-control for perishable products under service-level constraints, OR Spectrum, Vol. 32, No. 4, 979-996, doi:10.1007/s00291-010-0196-1

[24] Food and Agriculture Organization of the united Nations (FAO). FAOSTAT, from http://faostat.fao.org/site/339/default.aspx, accessed on 27-09-2015

[25] The World Bank. Data, from http://data.worldbank.org/indicator/EN.CO2.ETOT.MT, accessed on 15-04-2014

[26] Ministry of Electricity and Energy. Egyptian Electricity Holding Company. Annual Report 20112012, from $h t t p: / / w w w . m o e e . g o v . e g$, accessed on 15-04-2014

[27] US Environmnetal Protection Agency. Climate leaders GHG inventory protocol core module guidance, from www.epa.gov/climateleaders, accessed on 08-03-2015

[28] Scholz, K. (2013). Carbon Footprint of Retail Food Wastage - a Case Study of Six Swedish Retail Stores, Master's thesis, Swedish University of Agricultural Sciences, Uppsala 